\title{
Migratory bands give crickets protection
}

\section{Predators are not so lucky in picking out a flightless insect from a marching mass.}

$\mathrm{M}$ ormon crickets and juvenile locusts form huge migratory bands millions of individuals march in unison across the landscape ${ }^{1-3}$ and devastate vast agricultural areas, but little is known about why these bands form. Here we use radiotelemetry to show that band membership benefits these insects by greatly reducing the probability that they will become victims of predators. It is likely that migratory banding has evolved because it gives substantial protection to individuals within the group.

Protection against predators through mechanisms such as enhanced early detection, predator confusion and dilution of risk (the 'selfish herd' effect) has been proposed to account for the evolution and maintenance of large aggregations in animals ${ }^{4,5}$. The antipredator benefits of migratory-band formation have previously been assumed to be negligible ${ }^{3}$, but have never been quantified largely because of the difficulty of tracking individuals within bands and the rarity of witnessing predation events ${ }^{1,3,4}$. We have used radiotelemetry to overcome these problems.

The mormon cricket, Anabrus simplex, is a flightless katydid ${ }^{6}$, native to western North
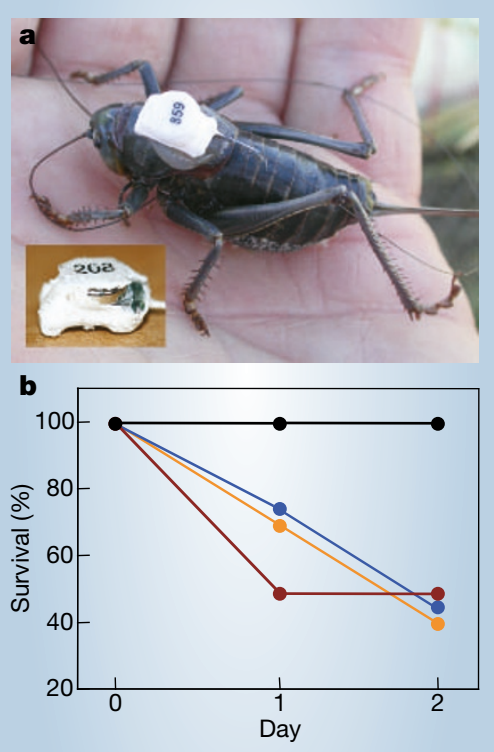

Figure 2 Radiotelemetric mark-recapture study reveals antipredator benefits for insects in migratory bands. a, Female mormon cricket with a 0.45 -g radiotransmitter glued to the pronotum. Inset, a recovered radiotransmitter showing evidence of predation, which in this case is likely to have resulted from chewing by a rodent. b, Survival of mormon crickets in a migratory band (black; $n=10$ for all replicates) compared with that of conspecifics transplanted away from the band (three replicate experiments: red, $n=10$; blue, $n=20$; orange, $n=20$ ). An equal number of males and females were used in each treatment and there was no effect of sex on survival (Cox regression, Wald statistic $=0.008$, d.f. $=1$, NS).

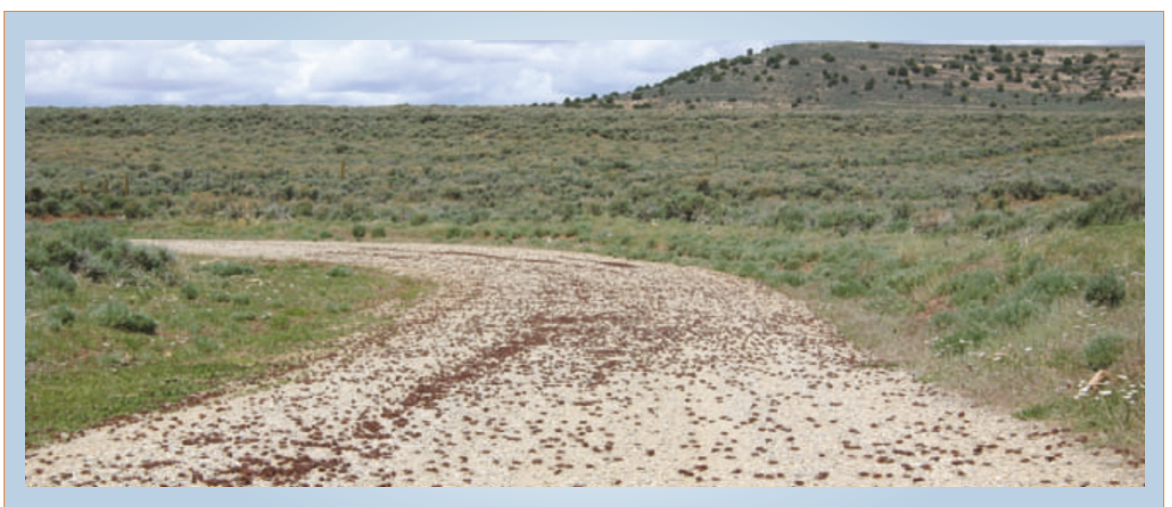

Figure 1 A migratory band of flightless mormon crickets (Anabrus simplex) crossing a dirt road in northeastern Utah, United States.

America, which forms spectacular migratory bands. These can be more than 16 kilometres long and several kilometres wide, with each square metre containing dozens of insects that walk up to $2 \mathrm{~km}$ a day ${ }^{2,7}$ (Fig. 1). In a replicated mark-recapture experiment, we compared the survival of individual mormon crickets in naturally occurring migratory bands with that of individuals transplanted from the band to nearby sites; mormoncricket bands had previously travelled through these sites, but they were empty at the time of the experiment. Individuals were located using small radiotransmitters ${ }^{8}$ (Fig. 2a), which enabled us to establish their fate with accuracy (for methods, see supplementary information).

Insects that had been translocated from the band suffered 50-60\% mortality due to predation over just two days in three replicate experiments (Fig. 2b). By contrast, we observed no mortality among individuals in the band during the same period, including among those crickets moved to control for any transportation effect (Life Table Survival analysis, Gehan's generalized Wilcoxon test: $P$ was $0.0118,0.0047$ and 0.0026 for three replicates, respectively; Fig. 2b).

Predation was evident from recovered radiotransmitters that had been partially chewed (Fig. 2a, inset) and often had body parts still attached; they were retrieved from trees and burrows, suggesting that birds and rodents are likely predators ${ }^{2}$. Two radiotransmitters were never recovered, presumably because of predator damage or removal from our detection range.

The evolution and maintenance of migratory-band formation requires the fitness benefits of group living to outweigh its costs ${ }^{4}$. Our results indicate that band formation confers a major anti-predator benefit, but what are the costs? Although difficult to quantify, intraspecific competition for resources is assumed to be a cost of group living and can account for group movement to exploit new resources ${ }^{1,3,4}$. Intraspecific competition in mormon-cricket bands mediates a food-stress-induced reversal of courtship roles at high population densities $^{7,9}$. Mormon crickets are also notoriously cannibalistic and likely to attack immobile conspecifics $^{2,7}$. Without discounting other hypotheses ${ }^{4}$, our results indicate that aggregation and constant movement protect band members from predators while reducing costs due to competition for resources and cannibalism. They also support a general antipredator role for outbreaks such as those in periodical cicadas, where synchronized, mass emergence reduces predation on individuals by sating local predators ${ }^{10,11}$.

Gregory A. Sword ${ }^{\star}$, Patrick D. Lorch $\dagger$, Darryl T. Gwynneł

*Northern Plains Agricultural Research Laboratory, US Department of Agriculture, Agricultural

Research Service, Sidney, Montana 59270, USA

e-mail: gsword@sidney.ars.usda.gov

$\dagger$ Department of Biology, University of North

Carolina at Chapel Hill, Chapel Hill, North

Carolina 27599-3280, USA

$\$$ Biology Department, University of Toronto at

Mississauga, Mississauga, Ontario L5L 1C6, Canada

1. Uvarov, B. P. Grasshoppers and Locusts Vol. II (Centre for Overseas Pest Research, London, 1977).

2. MacVean, C. M. in Integrated Pest Management on Rangeland: A Shortgrass Prairie Perspective (ed. Capinera, J. L) 116-136 (Westview, Boulder, Colorado, 1987)

3. Dingle, H. Migration: The Biology of Life on the Move (Oxford Univ. Press, Oxford, 1996).

4. Krause, J. \& Ruxton, G. D. Living in Groups (Oxford Univ. Press, Oxford, 2002)

5. Hamilton, W. D. J. Theor. Biol. 7, 1-52 (1971).

6. Sword, G. A. Anim. Behav. 69, 437-444 (2005).

Gwynne, D. T. Katydids and Bush-Crickets: Reproductive

Behavior and Evolution of the Tettigoniidae (Cornell Univ. Press, Ithaca, New York, 2001).

8. Lorch, P. D. \& Gwynne, D. T. Naturwissenschaften 87, 370-372 (2000).

9. Gwynne, D. T. Ecology 74, 1406-1413 (1993).

10. Karban, R. Ecology 63, 321-328 (1982).

11. Williams, K. S., Smith, K. G. \& Stephen, F. M. Ecology 74, 1143-1152 (1993).

Supplementary information accompanies this communication on Nature's website.

Competing financial interests: declared none. 